\title{
Impairment of 'ileostomy adaptation' in patients after ileal resection
}

\author{
G. L. HILL, W. S. J. MAIR, AND J. C. GOLIGHER \\ From the University Department of Surgery, The General Infirmary, Leeds 1, England
}

SUMMARY Ileostomists claim that in the months following the establishment of an ileostomy, the faecal output decreases in volume and becomes less fluid. It is claimed that this 'ileostomy adaptation' does not occur in those patients who have had an ileal resection.

To determine whether ileostomy adaptation does occur and to examine its physiological mechanisms, 10 ileostomy patients were studied. Five had had an ileal resection and five had not. The output of fluid, sodium, and potassium from the ileostomy was studied in each patient for the first 11 days after ileostomy and again at six months.

Those patients in whom the terminal ileum was preserved had small faecal outputs of fluid and sodium from the outset, and the water content of the effluent was significantly less at six months. After rapid expansion of the extracellular fluid by intravenous saline, there was a marked increase in faecal volume and sodium output.

In those patients with an ileal resection, the faecal volume and sodium output were more than two and a half times greater than those for the non-resected group. At six months there was no change in either the volume or chemistry of the effluent. After intravenous saline, no faecal response was observed.

It is therefore concluded that ileostomy adaptation does occur and it is a response of the intestine to conserve body salt. This response is lacking in ileostomists who have had an ileal resection.

After the establishment of an ileostomy, the discharge at first is very liquid and voluminous. After about a week the faecal losses gradually diminish and at the same time become much firmer. By the end of seven to 10 days the quantity of faeces is reduced to that of a long established ileostomy (Smiddy, Gregory, Smith, and Goligher, 1960). The consistency, volume, and concentrations of sodium and potassium appear to be similar to the long established ileostomy (Smiddy et al, 1960; Nuguid, Bacon, and Boutwell, 1961; Kanaghinis, Lubran, and Coghill, 1963; Kramer, Kearney, and Inglefinger, 1962).

There are, however, two clinical observations which have not been accurately measured or adequately explained. First, physiological adaptation is said to occur in which the ileostomy output decreases in volume and becomes less fluid in the months following operation (LeVeen, Lyons, and Becker, 1962). Secondly, surgeons generally hold

Received for publication 23 August 1974. the view that if the terminal ileum has been resected, then the ileostomy volume will be greater and the patient is more prone to salt and water loss (Nuguid et al, 1961). The present study in which 10 patients were followed from the day when the ileostomy was first established until six months after operation was designed to examine these two observations and to throw some light on their possible mechanisms.

\section{Materials and Methods}

Table I describes the relevant clinical data concerning each of the 10 patients and the type of operation performed. In all patients the surgery was elective and an everting type of ileostomy was performed using a standard technique (Goligher, 1967). Except in patients numbers 3, 8, and 9, who had no steroids, the operative period was covered by hydrocortisone administration, $100 \mathrm{mg}$ every six hours, and the dosage was then tapered rapidly to be discontinued or minimal by the seventh postoperative day. 982 


\begin{tabular}{|c|c|c|c|c|c|}
\hline Patient & $\operatorname{Sex}$ & Age & Final Diagnosis & Operation Performed & $\begin{array}{l}\text { Perioperative } \\
\text { Steroids }\end{array}$ \\
\hline $\begin{array}{l}1 \\
2 \\
3 \\
4 \\
5 \\
6\end{array}$ & $\begin{array}{l}\mathbf{F} \\
\mathbf{F} \\
\mathbf{M} \\
\mathbf{F} \\
\mathbf{F} \\
\mathbf{M}\end{array}$ & $\begin{array}{l}58 \\
63 \\
30 \\
41 \\
42 \\
26\end{array}$ & $\begin{array}{l}\text { Granulomatous disease } \\
\text { Ulcerative colitis } \\
\text { Ulcerative colitis } \\
\text { Ulcerative colitis } \\
\text { Ulcerative colitis } \\
\text { Ulcerative colitis }\end{array}$ & $\begin{array}{l}\text { Ileostomy and proctocolectomy } \\
\text { Ileostomy and proctocolectomy } \\
\text { Ileostomy and proctocolectomy } \\
\text { Ileostomy and proctocolectomy } \\
\text { Ileostomy and proctocolectomy } \\
\text { Ileostomy, proctocolectomy, } \\
\text { and } 7 \text { in. ileal resection }\end{array}$ & $\begin{array}{l}\text { Yes } \\
\text { Yes } \\
\text { No } \\
\text { Yes } \\
\text { Yes } \\
\text { Yes }\end{array}$ \\
\hline 7 & $\mathbf{M}$ & 27 & Ulcerative colitis & $\begin{array}{l}\text { Ileostomy, proctocolectomy, } \\
\text { and } 27 \text { in. ileal resection }\end{array}$ & Yes \\
\hline 8 & $\mathbf{M}$ & 33 & Granulomatous disease & $\begin{array}{l}\text { Ileostomy, rt hemicolectomy, } \\
\text { and } 48 \text { in. resection }\end{array}$ & No \\
\hline 9 & $\mathbf{M}$ & 31 & Granulomatous disease & $\begin{array}{l}\text { Ileostomy, rt hemicolectomy, } \\
\text { and } 24 \text { in. ileal resection }\end{array}$ & No \\
\hline 10 & $\mathbf{M}$ & 38 & Granulomatous disease & $\begin{array}{l}\text { Ileostomy, proctocolectomy, } \\
\text { and } 18 \text { in. ileal resection }\end{array}$ & Yes \\
\hline
\end{tabular}

Table I Clinical data

\section{Study I}

During the first 11 postoperative days, daily 24-hour faecal and urine collections were made, and the daily volume, sodium, and potassium outputs were determined. In the case of faeces the electrolyte concentrations were measured by a Technicon AutoAnalyzer on a filtrate of aqueous homogenate. The water content of the faeces was determined by taking aliquots by weight and transferring them to porcelain evaporating basins and drying to constant weight at room temperature in a dessicator, the process taking several days. By allowing for the added water, the water content of the ileostomy fluid was calculated from the formula:

$$
\% \text { water }=100\left(1-\frac{\mathrm{D}(\mathrm{F}+\mathrm{W})}{\mathrm{FA}}\right)
$$

where $A$ is weight of aliquot, $D$ its weight after drying, $F$ the weight of ileostomy fluid, and $\mathrm{W}$ the weight of added distilled water.

\section{Study II}

After discharge, the patients were followed at the outpatient clinic. Each patient gained weight and made rapid progress and in none were there any signs of recurrent disease. At six months after operation each was readmitted to hospital where he was observed under normal conditions, with no alteration in his usual diet or daily routine for a period of three days, except that no added salt was permitted with the food. On the fourth day each was given 460 m-equiv sodium in 3 litres of water intravenously over a 12-hour period. Collections were continued for a further three days. The results were statistically evaluated within the groups by comparing the changes for each individual and applying the paired $t$ test. Mean values for the two groups and 1 SD were also calculated and are shown to simplify the presentation of results.

\section{Results}

\section{VOLUME}

Table II shows the mean daily faecal volume for each patient for the seventh to the 11th postoperative days and for the second study period. Volumes for the first six postoperative days are so variable that a meaningful statistical treatment is not possible (figs 1 and 2).

The mean 24-hour faecal volume for days 7-11

\begin{tabular}{|c|c|c|c|c|}
\hline \multirow{2}{*}{ Patients } & \multirow{2}{*}{$\begin{array}{l}\text { Length of Ileum } \\
\text { Resected (in.) }\end{array}$} & \multicolumn{3}{|l|}{ Volume $(m l)$} \\
\hline & & $\begin{array}{l}\text { Study I } \\
\text { Days 7-11 }\end{array}$ & $\begin{array}{l}\text { Study II } \\
\text { Control }\end{array}$ & $\begin{array}{l}\text { Study II } \\
\text { After Saline }\end{array}$ \\
\hline $\begin{array}{r}1 \\
2 \\
3 \\
4 \\
5 \\
6 \\
7 \\
8 \\
9 \\
10\end{array}$ & $\begin{array}{r}2 \\
2 \\
2 \\
2 \\
2 \\
7 \\
27 \\
48 \\
24 \\
18\end{array}$ & $\begin{array}{r}680 \pm 194 \\
265 \pm 49 \\
620 \pm 44 \\
364 \pm 60 \\
496 \pm 169 \\
936 \pm 318 \\
920 \pm 51 \\
699 \pm 220 \\
1011 \pm 348 \\
1167 \pm 110\end{array}$ & $\begin{array}{r}386 \pm 38 \\
470 \pm 127 \\
572 \pm 84 \\
360 \pm 246 \\
388 \pm r 3 \\
685 \pm 176 \\
1050 \pm 57 \\
843 \pm 120 \\
1590 \pm 71 \\
1490 \pm 282\end{array}$ & $\begin{array}{r}648 \pm 24 \\
572 \pm 68 \\
688 \pm 45 \\
399 \pm 218 \\
460 \pm 94 \\
785 \pm 64 \\
1075 \pm 64 \\
815 \pm 63 \\
1448 \pm 270 \\
1375 \pm 186\end{array}$ \\
\hline
\end{tabular}

Table II The mean daily fuecal volume $( \pm 1 S D)$ calculated for each study period 

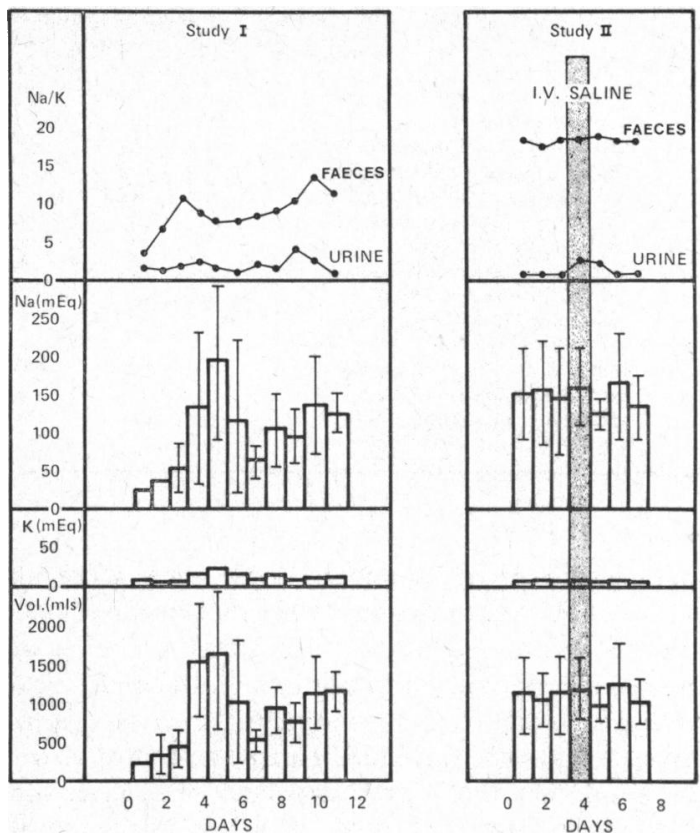

Fig 1 Day-to-day faecal and urine electrolyte values in the period following surgery $(I)$ and six months following surgery (II) in five patients who had an ileal resection.

inclusive after surgery for the 10 patients was $695 \pm 355 \mathrm{ml}$. After six months the mean daily faecal volume for the whole group had risen but not altered significantly (743 $\pm 477 \mathrm{ml})$; nor was there a statistically significant change after intravenous salt loading $(830 \pm 400 \mathrm{ml})$. Thus, for the group as a whole, there was no significant decrease in the ileostomy volume over the six-month period, nor was any significant intestinal adaptation uncovered by intravenous saline loading. However, there is a marked difference in the mean daily faecal output of those patients who have had an ileal resection (patients 6-10). Thus, for patients 1-5 (table II), the mean daily faecal output during postoperative days $7-11$ was $456 \pm 181 \mathrm{ml}$ compared with $909 \pm 337 \mathrm{ml}$ for patients 6-10 during the same period $(\mathrm{P}<0.001)$.

Similarly, at six months for the second study control period, the low daily faecal output for those patients without an ileal resection is significantly different to the high output measured for those patients with the terminal ileum resected $(430 \pm 136$ $\mathrm{ml}$ in the nonresected group compared with $1105 \pm 388 \mathrm{ml}$ for the resected group $(P<0.001)$.

Although there was no response to intravenous saline loading in the resected group $(1105 \pm 388 \mathrm{ml}$ to $1102 \pm 362 \mathrm{ml}$ after saline), there was a significant
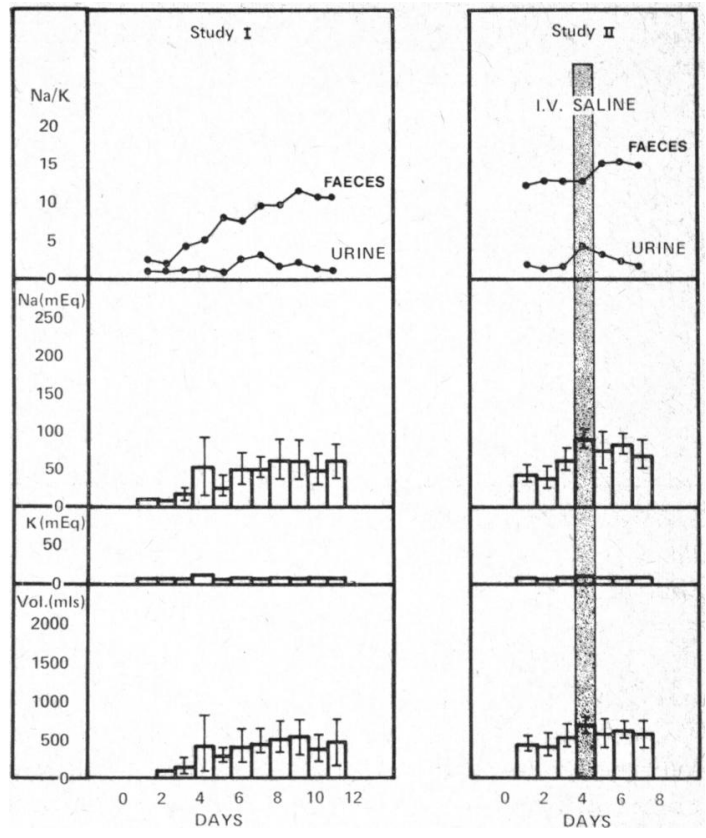

Fig 2 Day-to-day faecal and urine electrolyte values in the period following surgery $(I)$ and six months following surgery (II) in five patients who had not had an ileal resection.

increase in the mean daily faecal volume in those patients who had not had an ileal resection (from $430 \pm 136 \mathrm{ml}$ to $553 \pm 150 \mathrm{ml}, \mathrm{P}<0.025)$.

Thus, the resected group not only had a higher mean daily faecal volume from the very outset (fig 1) but intravenous saline loading fails to uncover any meaningful adaptation of the intestineafter six months when the ileostomy is established. However, those patients in whom the terminal ileum is preserved have not only a smaller volume ileostomy from the outset (fig 2) but at six months an intestinal adaptation is uncovered when the extracellular fluid volume is rapidly expanded by intravenous saline loading. Those patients who were not on steroids during the early operative course $(3,7,8)$ did not appear to have any major differences in mean daily faecal volumes during the first postoperative week when compared with the patients who were on steroids, but much variability during this period, not only between patients but also for the same patient, makes this evaluation difficult.

\section{WATER}

Table III shows a significant fall in water content of the ileostomy fluid between the first and second postoperative weeks for both the resected and non- 


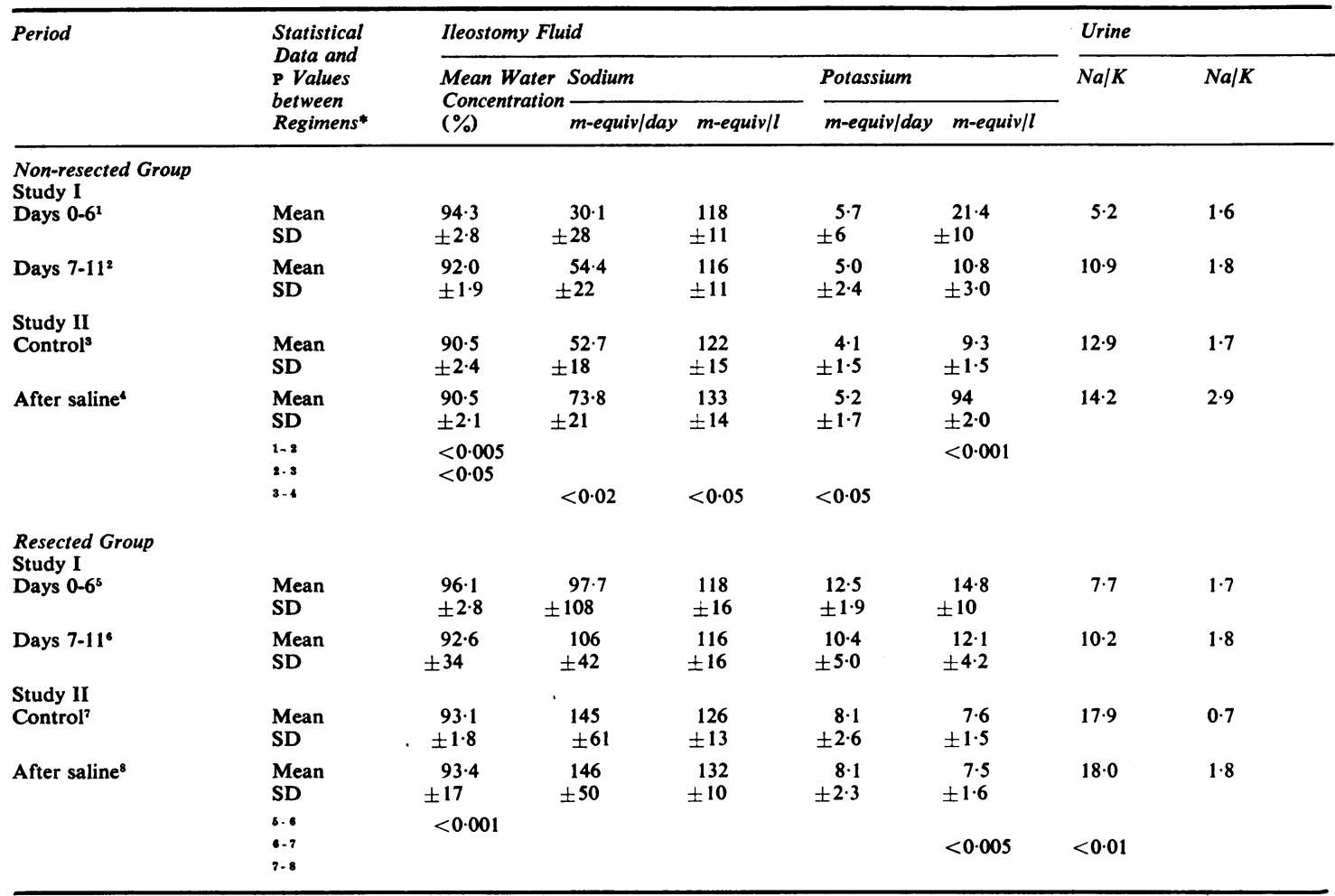

Table III Ileostomy chemistry during studies I and II comparing patients without and with ileal resection

${ }_{*}^{*} \mathbf{P}$ value given only where significant changes occur.

resected groups. Furthermore, in the nonresected group there is another significant fall in water content of the ileostomy fluid over the six-month period following surgery $(92.0 \pm 1.9 \%$ to $90.5 \pm 2.4 \%$, $P<0.05$ ), but a similar fall is not seen in those patients who had an ileal resection. The water content is also lower $(90.5 \pm 2.4 \%)$ at six months in the nonresected group when compared with the resected group $(93.1 \pm 1.8 \%$, $\mathrm{P}<0.01)$. There is no change in the water content of the ileostomy fluid in either group after intravenous saline loading. Thus, whereas there was a significant thickening of the ileostomy fluid after six months in those patients who had low volume ileostomies, no such decrease in water content occurred in those with a high volume ileostomy, apart from a significant fall in water content which occurred at the end of the first postoperative week.

\section{SODIUM}

For both study periods the sodium output of the resected group was significantly higher than for those who had not had an ileal resection (table III). The concentration of sodium in the ileostomy fluid, however, was almost identical in the two groups demonstrating that the increased faecal sodium loss in the resected group is related to the higher daily faecal output. There was no apparent conservation of sodium observed in either group over the six-month period, but after intravenous saline there was a significant increase in the daily output and concentration of sodium in those patients in whom the ileum had been preserved; a similar response was lacking in the patients with ileal resection (table III). The sodium concentration of the ileostomy fluid was not significantly different in those patients who were on high doses of steroids during the first six postoperative days.

\section{POTASSIUM}

The daily faecal output of potassium was not significantly different for any of the study periods or between the resected and nonresected groups. However, in the patients without an ileal resection there was a marked and significant increase in potassium concentration in the ileostomy fluid for the first six postoperative days, but after the first week 
this had returned to a normal volume of around 9 or $10 \mathrm{~m}$-equiv/l (table III). The only other significant change in potassium concentration observed was in the resected group, where over the six-month period following surgery there was a decrease in the potassium concentration of the ileostomy fluid from $12 \cdot 1 \pm 4.2$ m-equiv/l to $7.6 \pm 1.5$ m-equiv/l, $P<0.005)$.

Although the nonresected patients who were on steroids during the first study period had faecal potassium concentrations which were not significantly different to those of the nonresected patient who was not on steroids there was a marked difference in the resected group between those who were on and those who were not on steroids $(21.8 \pm 2.3$ m-equiv/l compared with $6.3 \pm 8.6$ m-equiv/1, $\mathrm{P}<0.001$ ).

\section{SODIUM/POTASSIUM RATIO}

Table III shows the close similarity of the sodium/ potassium ratio between the two groups for both faeces and urine during the first study period. After six months, however, the sodium/potassium ratio is lower in the urine for those patients with ileal resection $(P<0.05)$. This suggests that this group is conserving sodium more than the group without ileal resection, and mean daily outputs of sodium $(71 \cdot 1 \pm 35$ m-equiv in the nonresected group compared with $48 \cdot 7 \pm 16$ m-equiv in the resected group) and water $(1126.4 \pm 573 \mathrm{ml}$ in the nonresected group compared with $858 \pm 426$ in the resected group) support this statement, although statistical significance is not reached for either of these values because of marked variation in urine outputs from patient to patient. The reverse situation applied for faeces. For the high-volume patients with a resected ileum the sodium/potassium ratio at six months is high at 17.9 and responds little to intravenous saline loading (fig 1). In the low-volume nonresected group the sodium/potassium ratio in the faeces at six months remains lower and responds more dramatically to an intravenous saline load (fig 2). Whereas urine conservation of sodium occurs at the renal tubule in the resected group of patients at six months, it fails to occur in the intestine. It appears that there has been an 'escape' of the response to conserve sodium by the intestine in the resected group over the six-month period, whereas this conservation process has persisted in those patients without an ileal resection.

\section{Discussion}

This study demonstrates that ileal resection is associated not only with a high ileostomy volume but with an impairment of ileostomy adaptation.

Six months after surgery those patients with an ileal resection had mean daily ileostomy outputs of fluid and sodium more than two and a half times those of the nonresected group. Over this six-month period the ileostomy fluid thickened in those who had not had an ileal resection, but this adaptive process was not observed in the resected group. Significant conservation of fluid and sodium was uncovered by intravenous saline loading in the group in whom the ileum was preserved, but no similar response was noted in the resected patients.

The high ileostomy volume observed in the resected group is probably a direct result of significant loss of an absorptive epithelium known to be important in net transport of fluid and sodium (Sladen, Burland, and Samuel, 1972). However, since bilesalt feeding increases ileostomy volume(Miettinen and Peltokallio, 1971), it is possible that the high ileostomy volume noted in the present study is a consequence of a high bile salt concentration in the ileal fluid of those with ileal resection. Evidence that high concentrations of bile salts are present in ileostomy fluid after ileal resection is suggestive but not conclusive (Miettinen and Peltokallio, 1971; PercyRobb, Jalan, McManus, and Sircus, 1971).

Patients who have long-established ileostomies are susceptible to acute dehydration and sodium depletion (Gallagher, Harrison, and Skyring, 1962). It has also been demonstrated that ileostomy patients who are otherwise well suffer from chronic dehydration and sodium depletion (Clarke, Chirnside, Hill, Pope, and Stewart, 1967). Thus, it is not unexpected to find that the resected patients with a high volume of ileostomy fluid are depleted of sodium six-months after surgery. Not only is the urine sodium/potassium ratio significantly lower in those patients with an ileal resection, but direct body composition studies in these patients (to be presented) show a low total exchangeable sodium concentration in body water which is not present in those without an ileal resection.

Thus, it might be supposed that if ileostomy adaptation to body salt and water depletion occurs, it would be most marked in those with an ileal resection. However, significant adaptation is seen only in those patients in whom the ileum is intact. Although ileostomy volume does not decrease over the six-month period in either group, the water content is significantly less in those without an ileal resection. The increased output of fluid and sodium observed after rapid expansion of the extracellular compartment with intravenous saline in these five patients suggests a 'resting stimulus' whereby water and sodium are conserved by the terminal ileum.

The sodium/potassium ratio of the ileostomy fluid is lowest in both groups during the first postoperative week. Not only are the majority of patients on steroids during this period, but the metabolic 
response to the operation is maximal at this time. During the second postoperative week, when the metabolic response is passed, the steroids are discontinued, and the patient is taking food, the sodium/ potassium ratio rises to a level which is almost identical in the two groups. At six months, however, there has been a further and significant rise in the sodium/potassium ratio in the ileostomy fluid of the resected group in spite of a lower ratio in the urine.

This rise is not seen in the nonresected patients. The 'resting conservation' process originally present in the intestine of the resected group has been lost over the six-month period in spite of increasing body salt depletion.

Ileostomy adaptation to chronic salt and water depletion has been postulated (Clarke and Hill, 1966; Clarke, Hill, and MacBeth, 1967), and an increased ileal absorptive capacity for water has been demonstrated four months after the establishment of an ileostomy (Wright, Cleveland, Tilson, and Herskovic, 1969). The present study confirms that this adaptive process occurs, but is lacking in those who have had an ileal resection. Presumably, this process is mediated via aldosterone. Aldosterone and other salt-active steroids have a definite effect on ileal handling of fluid and electrolytes (Goulston, Harrison, and Skyring, 1963; Shields, Mulholland, and Elmslie, 1966; Kramer, and Levitan, 1972). Although aldosterone appears to stimulate jejunal absorption of sodium and water in the rat in vitro (Hill and Clarke, 1969; Crocker and Munday, 1969), there is no evidence tht this occurs in man. Therefore, the present findings of impaired ileostomy adaptation to body salt and water depletion after ileal resection may simply be a result of the removal of a significant length of that region of the intestine which responds most avidly to sodium depletion. There is no question that patients with an ileal resection can conserve fluid and sodium from the intestine, but it appears that the stimulus to do so must be particularly strong. This is suggested by the present study, in which this conservation process is not present in the resected patients after the initial powerful postoperative stimulus has passed, and by our previous study of a patient with an ileal resection who showed marked intestinal adaptation, but in whom profound body salt depletion was present (Clarke et al, 1967).

\section{References}

Clarke, A. M., Chirnside, A., Hill, G. L., Pope, G., and Stewart, M. K. (1967). Chronic dehydration and sodium depletion in patients with established ileostomies. Lancet, 2, 740-743.

Clarke, A. M., and Hill, G. L. (1966). The effect of intravenous salt loading on faecal volume and electrolyte content in patients with ileostomies. Proc. Univ. Otago med. Schl, 44, 51-53.

Clarke, A. M., Hill, G. L., and MacBeth, W. A. A. G. (1967). Intestinal. adaptation to salt depletion in a patient with an ileostomy. Gastroenterology, 53, 444-449.

Crocker, A. D., and Munday, K. A. (1969). Factors affecting mucosal water and sodium transfer in everted sacs of rat jejunum. J. Physiol. (Lond.), 202, 329-338.

Gallagher, N. D., Harrison, D. D., and Skyring, A. P. (1962). Fluid and electrolyte disturbances in patients with long established ileostomies. Gut, 3, 219-223.

Goligher, J. C. (1967). Surgery of Anus, Rectum, and Colon, 2nd ed., pp. 899-909. Bailliere, Tindall, and Cassell, London.

Goulston, K., Harrison, D. D., and Skyring, A. P. (1963). Effect of mineralocorticoids on the sodium/potassium ratio of human ileostomy fluid. Lancet, 2, 541-542.

Hill, G. L., and Clarke, A. M. (1969). The effect of aldosterone on mucosal transfer of sodium, potassium and water in the jejunum and ileum of the rat in vitro. Proc. Univ. Otago med. Schl, 47, 76-77.

Kanaghinis, T., Lubran, M., and Coghill, N. F. (1963). The composition of ileostomy fluid. Gut, 4, 322-338.

Kramer, P., Kearney, M. M., and Inglefinger, F. J. (1962). The effect of specific foods and water loading on the ileal excreta of ileostomised human subjects. Gastroenterology, 42, 535-546.

Kramer, P., and Levitan R. (1972). Effect of 9-a-Fluorohydrocortizone on the ileal excreta of ileostomized subjects. Gastroenterology, 62, 235-241.

LeVeen, H. H., Lyons, A., and Becker, E. (1962). Physiologic adaptation to ileostomy. Amer. J. Surg., 103, 35-41.

Miettinen, T. A., and Peltokallio, P. (1971). Bile salt, fat, water and vitamin $\mathbf{B}_{12}$ excretion after ileostomy. Scand. J. Gastroent., 6, 543-552.

Nuguid, T. P., Bacon, H. E., and Boutwell, J. (1961). Tne ileostomy: its physical characteristics and chemical behaviour. Dis. Colon Rect., 6, 293-296.

Percy-Robb, I. W., Jalan, K. N., McManus, J. P. A., and Sircus, W. (1971). Effect of ileal resection on bile salt metabolism in patients wil ileostomy following proctocolectomy. Clin. Sci., 41, 371-382.

Shields, R., Mulholland, A. T., and Elmslie, R. G. (1966). Action of aldosterone upon the intestinal transport of potassium, sodium and water. Gut, 7, 686-696.

Sladen, G. E. (1972). A review of water and electrolyte transport. In Transport Across the Intestine, edited by W. L. Burland and P. D. Samuel, pp. 14-34. Churchill Livingstone, London.

Smiddy, F. G., Gregory, S. D., Smith, I. B., and Goligher, J. C. (1960). Faecal loss of fluid, electrolytes, and nitrogen in colitis before and after ileostomy. Lancet, 1, 14-19.

Wright, H. K., Cleveland, J. C., Tilson, M. D., and Herskovic, T. (1969). Morphology and absorptive capacity of the ileum after ileostomy in man. Amer. J. Surg., 117, -42-245. 